\title{
Research on the Attribution and Cultivation of Contemporary College Students' Humanistic Quality
}

\author{
Hongxiang Zhao
}

School of economics and management, Shenyang University of Aeronautics and Astronautics

Keywords: Humanistic literacy, Missing attribution; Cultivate research

\begin{abstract}
Humanistic quality refers to the comprehensive quality or the degree of development that people have in humanities. In this article, firstly, $i$ will analyze the present situation and the importance of the college students' humanistic accomplishment, and then analyze the social environment, the educational idea, the family guidance, the reading habit and so on the reason leading to the lack of humanistic accomplishment, finally put forward from the traditional culture inheritance, the education curriculum system, And the purification of family and social and cultural environment in the promotion of college students in the humanities can take specific measures.
\end{abstract}

\section{The Meaning of Humanistic Quality}

Humanity refers to "the cultural phenomenon of human society". Adding knowledge into the human cognitive body and penetrating into human life and behavior called literacy. "Literacy" emphasizes ability derived from training and practice. Humanistic quality refers to people in the humanities have a comprehensive quality or to achieve the degree of development. Humanistic quality includes four aspects: (1) to have humanistic knowledge. (2) to understand the humanities. (3) master the humanities approach. (4) follow the humanistic spirit. We can define the humanities literacy as the three levels of humanistic literacy knowledge, humanistic accomplishment spirit and humanistic accomplishment behavior. These three levels includes and focus on each other. The connotation of humanistic accomplishment refers to the humanistic knowledge out of the temperament, outlook on life, world outlook, values, ideological grade, moral standards, psychological quality, interpersonal skills and other personality. Humanistic accomplishment is the host of the human spiritual homeland, and has the decisive effect on the human way of thinking, the psychological mechanism, the emotional world, the will ability, the value orientation, the aesthetic experience, the ideology and the ideal mode.

\section{Contemporary College Students Humanistic Status}

\section{The Ideal Faith Confused, the Pursuit of Vulgar Life.}

If the society is the sea, life is a boat, then the ideal belief is the pilot lighthouse and advancing sailing. No scientific ideals and beliefs of life, like the loss of the direction and power of the boat, wandering in the waves of life, and even sank in the rapids. Scientific and noble ideals and beliefs can guide the goal of life, to provide the driving force of life, improve the spiritual realm of life. However, some of current college students in the ultimate care of life without faith, the pursuit of material material, vulgarization. Specifically, some college students because of the lack of lofty ideals and beliefs of the guidelines and incentives, resulting in their short-sighted life goals, impetuous mind, quick success, inadvertently study, too. Some college students do not have the pursuit of noble value of life, covetous pleasure, using their parents sweat money to show lavish and pomp, only wealth in their mind, selfish, at the expense of selfish way to pursue their own goals.

\section{Lack of Human Knowledge, Lack of Humanistic Spirit.}

Many college students lack of cultural accomplishment, literary philosophy and artistic knowledge and other shallow, some science and engineering students lack of literary knowledge and artistic knowledge, the human cultural heritage, especially the Chinese nation's long history, fine traditions, excellent culture, science and technology development. With the influence of the national civilization, the cultural and artistic temperament, sentiment and character, some students' 
cultural grade is not high, the aesthetic ability is low, and the language expressive ability, the writing ability and the interpersonal ability and so on are seriously deficient.

\section{The Lack of Knowledge Level.}

At present, a considerable number of university students pay too much attention to the professional skills and practicability of the profession, while the theoretical knowledge of the nonutilitarian humanities and social sciences lacks the interest, and the enthusiasm of the curriculum of humanities and social sciences is not high, even despise these courses. They are willing to science and technology curriculum activities, shortage of humanities curriculum, proficient in the computer, in the human brain, the knowledge structure is very unreasonable, their traditional Chinese culture and the world's outstanding cultural thought know little or no knowledge, and thus lack the necessary view of history, national identity and open mind.

\section{The Lack of Capacity Level.}

Some students are concerned only with the study of professional theoretical knowledge, do not want to communicate with others, lack of mutual cooperation and cooperation, their ability to judge the value of logical thinking ability, self-learning ability, social practice is not strong, especially in the organization and coordination Innovation in these two aspects, the ability is relatively low, the performance of the overall quality and reality needs has a big gap, can not meet the rapid development of social needs of the times.

\section{The Necessity and Significance of College Students' Humanistic Cultivation}

From the relationship between natural science and humanities and social sciences, the natural science to solve the relationship between man and nature, is the dialogue between man and nature; Humanities and social science aim to solve the relationship between people and society. It is a dialogue between people. It is a kind of basic quality, which has a strong influence on the formation and development of other qualities, and has a strong penetration ability to promote the improvement of the comprehensive quality of college students. This is not only in improving the professional quality of college students, psychological quality, ideological and moral qualities, but also in the students to establish the correct values, nurturing national spirit, enhance non-intellectual factors such as several aspects. The cultivation of humanistic accomplishment is great significance for college students to form a sound personality, improve their way of thinking and break through narrow utilitarianism.

To promote the improvement of the overall quality of college students, in a sense, the professional competence, business quality is only the conditions for the comprehensive development of human beings, and humanistic quality, that is, ideological realm, spiritual sentiment, cognitive ability, cultural education is the most important sign of man's all-round development. Elegant humanistic cultivation can make students consciously care for others, caring society, caring for human beings, caring for the meaning and value of nature, and gradually have a sound personality, so that its comprehensive ability to be improved. If the professional ability of college students is the leaves, then the humanistic accomplishment is the rudder, only the target is correct, it could reach the success of the other side. Therefore, every college student should take the initiative, consciously improve their own humanities.

Strengthening the humanities of college students is also the world's higher education reform and hot spots. The industrial revolution in the human society to create a great material wealth at the same time, but also brought the distortion and depression of human nature, so that the spirit of science and humanistic divisions, to "rational first" point. The resources, environment, ecology and cultural crisis caused by the western modernization model have exposed the shortcomings of modern Western humanistic spirit, which makes the world's education circles generally realize that, in addition to disseminating knowledge, education is also responsible for giving people the right treatment of these knowledge, meanwhile the attitude is the mission! Rabelais said: "There is no conscience of science will only be the ruins of the soul." Based on this, the world, especially the developed countries, in order to prevent the emergence of single-sided, began to attach great importance to the cultivation of humanistic quality of college students. 


\section{The Current Stage of College Students Lack of Humanistic Reasons}

The Social Environment of the Quick Success. The market economy brought about by the utilitarian psychology growing global economic development is rapid, China's opening up to the outside world, the socialist market economy in-depth development, the diversification of social life, the interests of mutual friction, struggle, so that the current part of college students in the ideal faith. Orientation, social responsibility and other aspects caused many new situations and new problems. In real life, we found that the market-oriented economic environment associated with the interests of the orientation of some college students have produced a quick success, mercenary value of the standard, utilitarianism gradually eroded these college students, and they believe in the creed and ideas. The idea of quick success has brought about more or less adverse effects on the "view of learning" of contemporary college students in a certain range and extent. In the course of curriculum choice, they will pay more attention to those courses which have strong practicality and employment possibility.

Misleading Educational Philosophy. For a long time, we have not paid due attention to the value and function of humanistic education, and the lack of humanistic accomplishment of college students has become a grim reality that we have to face. Market orientation makes humanistic education difficult. With the establishment of China's market economic system, science and technology on the role of social development highlights, so that human science and technology worship, it seems that science and technology can solve all the problems faced by mankind, which makes the actual social education from college social education is difficult to affect the formation and improvement of college students personality, some people even doubt the necessity and importance of humanistic education. Our humanistic quality education not only lacks systematic planning and strategic arrangement on teaching materials, but also lacks scientific and pertinent educational methods. The former led to the cultural knowledge system fragmented, the university campus is to increase knowledge, enhance the cultivation, purification of the soul of the place, but through the college students "bedside book" type of investigation found that college students in addition to professional books, only foreign language, Computer, economy and how to interview, how social and other aspects of the books, as to improve their own quality of humanities books are few people interested.

The Guidance of the Family Level. In the era of today's only child, many parents for the future of the child has a success can not fail the psychological, in the child who sustenance too high expectations, hopeful ingenuity, and thus actively cooperate with the school's "examination "education. After the child went to college, the parents were eager to find out how to find a decent and rewarding job after graduation and recover the cost of education in the shortest possible time. As long as the test can get high marks, can find a good job after graduation, is the child's victory, their own success, as for the other, do not care.

Students Read Habits Have Undergone Major Changes. Since the 1990s, the network as a technical tool, at an alarming rate developed into a newspaper, film, television, the traditional mass media after the fourth largest media, its arrival has greatly changed the people living in the world. Changed the behavior of college students and information storage and communication. The network has gone deep into the study and life of college students, so that college students' reading psychology and behavior deviation, such as one - sided network reading cognition, unsound network reading motivation, paranoid reading behavior and other issues. Due to the explosive development and extensive application of the new media in the network, the reading habits of college students as young people have had a direct impact. The popularity of new media makes the contemporary college students take little time to read the classic classics both ancient and modern. Through the electronic media to read some of the humanities, reading the lack of planning, system and integrity 


\section{To Enhance the Cultivation of Human Resources and the Way and Methods}

Full Attention to the Traditional Culture of Education and Heritage. The Chinese nation has created excellent traditional culture with strong vitality. These traditional cultures not only reflect the lofty national spirit and national integrity, but also cover many fields such as philosophy, social sciences, natural sciences, literature and art. It has a deep impact on people's way of thinking, ideas and behavior patterns. Traditional culture is a national survival and development of the spirit of support, only to strengthen the national and traditional culture of education. In order to establish national self-esteem and self-confidence, the formation of the revitalization of the Chinese nation's historical sense of responsibility and identity. We must optimize the social environment, create a strong university campus culture and other means, so that students feel, understand, love and inherit the excellent traditional culture, so that the essence of traditional culture in their body to carry forward, from generation to generation.

Improve the Humanities Education Curriculum System. It is necessary to strengthen the humanistic education consciousness of the university managers, and to keep the humanistic education concept of the managers of the humanities, to attach great importance to the humanistic literacy education of college students and put them on the important position. Only in this way, we can really ensure that the humanities education in colleges and universities to achieve the desired results. Actively explore the effective variety of curriculum organization. For some of the relatively wide range of disciplines, knowledge capacity is relatively large humanities education courses, you can refer to the central content or the subject area, design a series of courses; and for some disciplines are not wide, knowledge capacity is relatively small courses and can be implemented in one or more lectures. This will not only save the teaching time and educational resources, but also can improve the practical effect of humanistic teaching. The teaching method of innovative humanistic curriculum, on the basis of playing the "instrumental" function of traditional classroom, more excavates the "guiding function" of the classroom and helps the contemporary students to internalize humanistic knowledge into humanistic accomplishment. In the teaching activities, we should actively promote the discussion, heuristic and other teaching methods, so that students take the initiative to participate in the experience, stimulate students 'interest in learning, the development of students' potential.

To Improve the Humanistic Qualities of Teachers' Humanities. The level of teachers' knowledge not only includes the depth and breadth of their professional research, but also the teachers' deep understanding of the national humanistic spirit, the accurate grasp of the national history and culture, and the ease in the actual teaching process. The teacher's personality charm can be directly on the students have a silent impact. A teacher of modesty, knowledge of the book, full of love, a better aesthetic experience and rich emotional teachers, his gestures are reflected between the wisdom of light, human nature of the warmth of such teachers must be students like teachers. Its personality charm as tight as the magnetic field to attract students, affecting the formation of the humanities of students.

To Guide Students to Take the Initiative to "Create Self". It is the key link to improve the level of humanistic accomplishment of contemporary college students. Participating in social practice students regularly or irregularly participate in social activities such as welfare, nursing homes, kindergartens and other activities to carry out some voluntary activities to their own experience to improve the cultural quality of this part of the growing college students is particularly important. The Regularly set up a series of lectures on humanities knowledge. To guide students to read the cultural classics as an interest, as its own comprehensive development of an inherent need. On this basis, the external campus culture environment, for its successful construction of a variety of forms of educational platform window, carefully set up humanistic quality education courses and other educational content, means and methods can really play a practical role. Therefore, it is necessary to set up the conditions and create the environment, so that they can take the initiative to carry out self-personality shaping, which is an indispensable and insurmountable stage of improving the humanistic accomplishment of contemporary college students. 
Purification of Family and Social and Cultural Environment. Needing to cooperate between family, society and university collaboration, so as to jointly promote the humanities education process, enhance the effectiveness of humanities education. From the family education point of view, we should guide the children to establish the correct concept of humanities, and personally, for the children to create a conducive to enhance their cultural literacy family atmosphere. From the perspective of social education, we must correctly recognize the social impact of the ideological and cultural atmosphere on the contemporary college students to enhance the humanities. At the national level, the government should strengthen the propaganda of public opinion on the quality education of college students, and continuously promote the development of humanistic quality education.

\section{References}

[1] LiXiaoli. Discussion of Teaching Diverse Teaching Methods of Probability and Statistics [J]. University Mathematics, 2005, 21(4): 33-35

[2] SunFengqi. Discussion on Teaching Reform of Higher Mathematics [J]. Journal of Jilin normal university, 2005(1):109-110

[3] LinZhengyan. Some Suggestions of Curriculum Reform of Probability and Statistics [J]. Studies In College Mathematics, 2001, 4(1):6, 30

[4] LiePuyan. Education and Teaching Reform of Higher Mathematics [J]. Sun Yatsen University Forum, 2005, 25(3):12-14

[5] ShiQingsheng. Teaching Reform and Practice of Probability and Mathematical Statistics Course [J]. Journal of Nanjing University of Technology (social science edition), 2004(3):9496

[6] LiuGuoqing. Reforming Classroom Teaching Method to Explore Optimal Teaching Mode of Probability and Statistics [J]. University Mathematics, 2003, 19(3):27-29 